\title{
Enhancing the anode performance of microbial fuel cells in the treatment of oil-based drill sludge by adjusting the stirring rate and supplementing oil- based drill cuttings
}

\section{Qi Feng}

Chongqing University

\section{Longjun Xu ( $\nabla$ xulj@cqu.edu.cn )}

Chongqing University https://orcid.org/0000-0001-7469-9721

Chenglun Liu

Chongqing University

\section{Yu Hao}

Chongqing Vocational Institute of Engineering

\section{Zhengxin Yang}

Chongqing University

\section{Teng Zhang}

Chongqing University

\section{Yanling Liu}

Chongqing University

\section{Huaren Su}

Chongqing University

\section{Research Article}

Keywords: Microbial fuel cell, Stirring rate, Oil-based drill cuttings, Oil-based drill sludge, Electrogenic bacteria, Electricity generation performance

Posted Date: May 10th, 2021

DOl: https://doi.org/10.21203/rs.3.rs-457734/v1

License: (-) (i) This work is licensed under a Creative Commons Attribution 4.0 International License. Read Full License 


\section{Abstract}

This was the first attempt to investigate the bioelectricity output based on solid-liquid cooperation in the microbial fuel cell (MFC) treatment of oil-based drill sludge by adjusting the stirring rate (SR) and supplementing oil-based drill cuttings (OBDCs). According to the results, the maximum power density output reached $671 \mathrm{~mW} / \mathrm{m}^{2}\left(5.4 \mathrm{~kW} \mathrm{~h} / \mathrm{m}^{2}\right)$ when the stirring rate was $100 \mathrm{r} / \mathrm{min}$ and the OBDCs concentration was $2 \mathrm{~g} / \mathrm{L}$ in the anode chamber, which was more than 2.4 times as high as that of the control group and significantly higher than those of other MFCs. Extremely high removal efficiencies of chemical oxygen demand (COD), ammonia and total inorganic nitrogen (TIN) were realized in optimization, with values of $52.3 \pm 1.9 \%$ (the removal quality was $12081 \pm 432 \mathrm{mg} / \mathrm{L}$ ), $74.5 \pm 0.2 \%$ and $58.9 \pm 0.2 \%$, respectively. Electrochemical analyses and high-throughput sequencing revealed that the cooperation of stir with OBDCs could activate microbial activity while reducing the overpotential loss in anode systems and thus responsible for the enrichment of electrogenic bacteria with extracellular electron transfer functions (such as

Proteobacteria, Bacteroidetes and Actinobacteria) and denitrifying bacteria (such as Bacilli and Anaerolineae and Rhodopseudomonas). Moreover, substrate characterization (via Fourier-transform infrared spectrometry (FT-IR) and X-ray diffraction (XRD)) showed that organic matter might converted into small molecules without intermediates. This investigation offers a new strategy for the treatment /application of solid and liquid produced from oil and gas fields by bioelectrochemical technology.

\section{Introduction}

Oil-based drill sludge (OBDS) is a special byproduct of shale gas fracturing, drilling, and cementing processes (Lin et al. 2020), and it is usually in the form of a stable emulsified dispersion system that is composed of large amounts of petroleum hydrocarbons, synthetic mineral oil, water phase and metals. Hence, OBDS has been listed as a national hazardous waste in China. The development of technologies for treating or applying OBDS is urgent necessity. A series of methods for degrading this type of waste have been proposed, such as pyrolysis (Rajaković \&Skala 2006, Suchocki et al. 2021), thermochemical cleaning (Lu et al. 2020), ultrasound (Zhang et al. 2021) and microwave radiation (Rajaković \&Skala 2006). Pyrolysis has become an efficient method and is used widely in the United States, Canada and other countries. However, it required a higher temperature (above $550{ }^{\circ} \mathrm{C}$ ) and reactors with complex processes, which only produce bio-oils on a small scale. Therefore, the development of an economical, efficient and environmentally friendly approach for degrading OBDS has become inevitable.

Microbial fuel cells (MFCs) are a new electrochemical technology that is based on biomass regeneration and can treat waste via anaerobic or facultative aerobe microbe metabolism while simultaneously harvesting electric energy directly from wastewater, and their use has been welcomed warmly in the environmental studies field over the last few years (Zhang et al. 2020d). Several limitations of two-chamber MFCs have been reported, such as a lower abundance of organisms and nitrogen in the sediment, electrodes with poor catalytic activity, strong internal resistance mass transfer effects and supplementation with materials that cannot accelerate microbial electricity generation (Matsumoto et al. 2020, Palanisamy et al. 2019, Wang et al. 2020). The output power density is affected by the organic matter in the sediment and electrogenic microbes in the electroactive biofilm (due to the capability of microorganisms to efficiently use the active 
materials from the electrode either as electron acceptors or donors through their extracellular electron transfer (EET) mechanisms) (Chiranjeevi \&Patil 2020). Recently, various types of wastewater with high concentrations of organic matter or nitrogen have been used as fuel in MFCs. These were partly collected from a sewage treatment plant (Jiaqi et al. 2020), a palm oil mill (Nor et al. 2015). In particular, Li et al (Li et al. 2020) treated oil wastewater by using a graphene modified titanium anode with microbial fuel cell that realized a peak power density of $576.4 \mathrm{~mW} / \mathrm{m}^{2}$ vegetable oil (Liu \&Vipulanandan 2017) and oil sewage (Yang et al. 2016) , but OBDS was not utilized.

Based on these results, OBDS is a potentially strong substrate for MFC, but the the tendency for solid accumulate at the bottom may decrease the performance (Nor et al. 2015). Therefore, reducing the mass transfer resistance of microorganisms has been the major focus of research activity (Chen et al. 2019). To overcome the harmful effects of low interaction efficiency between bacteria and anode material, studies have shown that high shear rates (below the tensile strength level) lead to stronger microbial aggregation and more compact bacterial colony structures (Jones \&Buie 2019, Pham et al. 2008, Pinck et al. 2020). High shear can be realized by prolonging hydraulic retention times (Gao et al. 2019), rotating anode electrodes (Pan et al. 2019) and applying agitation to the cathode chamber (Islam et al. 2019). For instance, it has been reported that the power and current densities of polydimethylsiloxane (PDMS)-based microscale MFCs increase with increasing flow rate and that maximum power densities and current densities were 0.71 $\mathrm{mW} / \mathrm{m}^{2}$ and $1.8 \mathrm{~mA} / \mathrm{m}^{2}$, respectively, which higher than that were realized by previous PDMS-based micro MFCs (Yoon et al. 2018). Therefore, agitation is vitally important for the performance improvement of sediment MFCs.

Supplementation with materials can activate microorganisms and further accelerate electron transfer in anode chambers. Exogenous electron shuttles such as disulfonate, chinone, riboflavin and neutral red have been demonstrated to facilitate indirect electron transfer to the anode. However, these mediators are usually costly, poisonous and easily washed away, thereby resulting in additional operational losses or unnecessary consumption (Peng et al. 2013). Goethite ( $\mathrm{a}-\mathrm{FeOOH}$, which is an iron oxide), magnetite and hematite, which have lower solubility in water, function mainly as promoters of EET acceleration. It has been demonstrated that the maximum power density of MFC with $5.0 \mathrm{Wt} \%$ a-FeOOH was $36.4 \%$ higher than that of an activated carbon control (Peng et al. 2013). Oil-based drill cuttings (OBDCs) often contain significant amounts of petroleum hydrocarbons ( $>30 \%), \mathrm{Fe}, \mathrm{Zn} \mathrm{Mg}$ and $\mathrm{Ba}$ et al heavy metals which are in ore form such as barite $\left(\mathrm{BaSO}_{4}\right)($ Chen et al. 2020), therefore, the addition of OBDCs might increase the electron migration rate and the abundance and diversity of electric bacteria in the microbial community. And to the best of the authors' knowledge, the treatment/disposal of OBDCs to mitigate the impacts on human health has not been fully investigated (Hu et al. 2020). Furthermore, to date, no study has examined the supplementation of oilassociated MFCs with OBDCs species. The present work is the first attempt to employ electromagnetic stirring and supplement OBDCs (OBDCs is a type of hazardous solid waste) simultaneously to boost and stabilize the power outputs and the metabolic functionality of MFCs in the treatment of OBDS. We also discussed the possible degradation process of organic matter and nitrogen in the substrate.

\section{Materials And Methods}




\subsection{MFC construction and operation}

An H-type two-chamber system was fabricated using plexiglass cells, and the effective anode and cathode chamber volumes were $800 \mathrm{~mL}$ throughout the study. Two-chamber MFCs were each separated by a proton exchange membrane (PEM) (Nafion 117, DuPont, America) with an effective area of $7 \mathrm{~cm}^{2}$. Graphite felt (Beihai Carbon Plant Co., Beihai, China) and carbon brush (Haote Co., Jingzhou, China) with a surface area of $2 \mathrm{~cm} \times 3 \mathrm{~cm}$ served as the anode and cathode, respectively.

The MFC cathode chamber was inoculated with the mixture of aerobic activated sludge (sewage treatment plant, Jingkou, Chongqing, China) with aged landfill leachate (municipal solid waste landfill, Changshengqiao, Chongqing, China) at a volumetric ratio of 3:1. The anode chamber was inoculated with anaerobic activated sludge derived from aerobic sludge that had acclimatized for 15 days, and headspace of the cell maintain oxygen-deprived during the process. The volumes of anode and cathode inoculation solution were both $600 \mathrm{~mL} .1 .6 \mathrm{~g} / \mathrm{L} \mathrm{CH}_{3} \mathrm{COONa}, 0.05 \mathrm{~g} / \mathrm{L} \mathrm{NH}_{4} \mathrm{Cl}, 12.5 \mathrm{~mL} / \mathrm{L}$ trace metal solution and $5 \mathrm{~mL} / \mathrm{L}$ vitamin solution were added as nutrients in the anolyte, and $1.0 \mathrm{~g} / \mathrm{L} \mathrm{NaHCO}_{3}, 0.2 \mathrm{~g} / \mathrm{L} \mathrm{NH}_{4} \mathrm{Cl}, 12.5 \mathrm{~mL} / \mathrm{L}$ trace metal solution and $5 \mathrm{~mL} / \mathrm{L}$ vitamin solution were added in catholyte. The specific procedures of inoculation and voltage record were performed according to the method of the our previous study (Feng et al. 2020). All cells were operated at $25 \pm 1^{\circ} \mathrm{C}$.

The MFCs were operated in continuous mode at the end of the inoculation cycle. The anaerobic activated sludge in the anode chamber was replaced with OBDS as the anode chamber substrate, and the cathode chamber substrate stay the same (the properties of the anolyte and catholyte are described in Tab. S1). 2 groups including 8 MFCs were operated for investigated the effects of SR rates and cuttings concentrations on the performance, (I) control group, with SRs of 50,100 , and $200 \mathrm{r} / \mathrm{min}$ by magnetic stirrers in anode chamber; (II) control group, with OBDCs at 1, 2, 4, and $6 \mathrm{~g} / \mathrm{L}$ applied to the anode area (The OBDS and OBDCs were obtained from the shale gas production well in Chongqing, China.). OBDCs is a black powder (as shown in Fig. S1 (a)) with a strong heavy oil taste and a complex elemental composition (Tab. S2). The pretreatment method of OBDCs before adding to anode chamber: the OBDCs are stirred evenly, and crushed into powder by ball mill, then dried in $60^{\circ} \mathrm{C}$ vacuum drying oven for 24 hours, finally filtered through standard sieve (aperture $<1.7 \mathrm{~mm}$ ) for standby. There is no need to add external nutrients to the anode chamber during operation. When the output voltage of the MFC decreased or the pollution removal effect did not change, the MFC operation was considered to be complete. At the end of the operation of the 8 MFCs, we identified the most suitable SR and OBDCs concentration for the final optimization experiment.

\subsection{Electricity generation performance and electrochemical analyses}

The output current density was calculated in accordance with Ohm's law. The internal resistance of the MFC was determined using the slope of polarization graphs, which were obtained by reducing the resistance in a specified step (decreased from 100000 to $10 \Omega$ ). The voltage and power density were plotted against the current density to obtain the polarization and power density graphs, respectively. Electrochemical impedance spectroscopy (EIS) was used to further investigate the composition of the apparent internal resistance, and the scanning frequency of EIS was $10^{-2} \sim 10^{5} \mathrm{~Hz}$. 
To better characterize the reasons of SR, OBDCs and their cooperation on the MFC performance, the electrochemical analysis was studied by CV and Tafel. Before conducting the electrochemical characterization experiments, the MFCs were disconnected from any constant load device and maintained under open circuit voltage (OCV) status for $30 \mathrm{~min}$. Cyclic voltammetry (CV) was conducted using an instrumental electrochemical workstation ( $\mathrm{CHI} 660$, Chenhua. Co., China) with a three-electrode system at a sweep rate of $10 \mathrm{mV} / \mathrm{s}$ unless otherwise specified, and the anode and cathode were connected to the working terminal and counter terminal, respectively. The initial potential of the Tafel curve was the OCV, with the scanning range being $\pm 100 \mathrm{mV}$ of the initial potential.

\subsection{Biofilm and substrate characterization}

The morphology of the biofilms was identified via scanning electron microscopy (SEM) (ZEISS SUPRA 40, Zeiss, Germany). Elemental compositions of biofilms and substrates (OBDS, and the mixture of OBDS of OBDCs) were analyzed employing energy dispersive spectrometry (EDS) (ZEISS SUPRA 40, Zeiss, Germany). Fourier- and X-ray diffraction (XRD) (Bruker D8, Germany) and transform infrared spectrometry (FT-IR) (Nicolet-iS10, Thermo Fisher, America) were used to analyze the functional groups and the phase structure of the substrates, respectively, the substrates was washed and then dried for 6 hours at $60{ }^{\circ} \mathrm{C}$ vacuum condition after the MFC operation.

\subsection{Microbial community analysis}

At the end of the operation, the biofilm on the anode chamber was collected using a pure DNA kit (Omega Cycle, America) and stored in a refrigerator at $-80^{\circ} \mathrm{C}$ before the high throughput sequencing. The construction of the 16S rRNA gene library and the bioinformatics analysis are described in detail in the supplementary material (Section 1).

\subsection{Test and calculation}

The monitoring and calculation of the concentrations of pollutants (COD, $\mathrm{NH}_{3}-\mathrm{N}$, and , among) and electrical performance tests (e.g., voltage output, power generation, and polarization curves) were performed as described in a previous study (Gonzalez et al. 2021). The current density, power density, exchange current density and coulombic efficiency (CE) were calculated according to a previous study (Yellappa et al. 2020) and presented in the data analysis section of supplementary materials (Section 2).

\section{Results And Discussion}

\subsection{Effect of SR on the electricity generation performance}

Following the operation period, the output voltages of MFCs at various SRs were presented in Fig. 1(a). The voltage oscillated significantly initially but quickly recovered at 50,100 and $200 \mathrm{r} / \mathrm{min}$, and in the plateau state, the average voltage that was generated at $100 \mathrm{r} / \mathrm{min}$ reached $589 \mathrm{mV}$, which is approximately 2.5 times higher than that generated at $200 \mathrm{r} / \mathrm{min}$ (higher shear stress). In contrast, the MFC steadily outputted until the end of the operation in the control group. Thus, stirring at a suitable rate substantially increased the substrate and microbial transfer to the electrode and proton diffusion from the anodic reaction to the 
cathode, which was favorable for the growth and metabolism of anaerobic or facultative electrogenic bacteria.

To more accurately evaluate the bioelectricity outputs of various MFCs, the power density and polarization are presented in Fig. 1 (b) and Fig. 1 (c), respectively. The best bioelectricity performance was obtained for the MFC with stirring at $100 \mathrm{r} / \mathrm{min}$ (the maximum power density of $610 \mathrm{~mW} / \mathrm{m}^{2}$ ), which substantially exceeded those of other MFCs. This is because reducing the mass transfer resistance often increases the metabolic efficiency of electricigens in the substrate and the proton transfer between the anode and cathode chambers (Yu et al. 2021). However, dissolved oxygen easily diffused into the anode area at $200 \mathrm{r} / \mathrm{min}$, which severely disturbed microbial activity and simultaneously decreased the reduction potential and the electron acceptance capacity of the cathode. The maximum power density in the present study exceeded 13 times that in a previous report that applied crude oil as the MFC substrate (Nandy et al. 2020); thus, OBDS has substantial development potential in the field of MFCs and lays a strong foundation for follow-up investigation.

Based on Fig. 1(c), the apparent internal resistances were 601, 415, 435, and $973 \Omega$ in the control group and the groups with stirring at $50 \mathrm{r} / \mathrm{min}, 100 \mathrm{r} / \mathrm{min}$ and $200 \mathrm{r} / \mathrm{min}$, respectively. To further examine and identify the composition of the total internal resistance, the equivalent circuit (Tab. 1) was obtained with fitting data through Nyquist diagrams (Fig. 1 (d)) of various MFCs. The charge transfer resistance (Rct) represents the resistance to the kinetics of electrochemically controlled reactions that are associated with the transfer of electrons. It was found that an Rct of $100 \mathrm{r} / \mathrm{min}(266.5 \Omega)$ was the minimum among all cases, and the solution resistance (Rs) of $200 \mathrm{r} / \mathrm{min}$ was a little more than those of the other MFCs. This result suggested that the key factor that affected the electrochemical activity, hence the metabolic rate of substrates was Rct instead of Rs, which was consistent with the results of a previous study (Zhou et al. 2020). The lower Rct further indicated that the shear resistance significantly decreased the diffusion of $\mathrm{H}^{+}$and products from the anode surface to the main solution, thereby improving the power density and output voltage. In summary, the optimal SR in the MFCs was $100 \mathrm{r} / \mathrm{min}$.

Tab. 1 Fitting parameters value in EIS with different SRs.

\begin{tabular}{|lllll|}
\hline & control group & $50 \mathrm{r} / \mathrm{min}$ & $100 \mathrm{r} / \mathrm{min}$ & $200 \mathrm{r} / \mathrm{min}$ \\
\hline Rct $(\Omega)$ & 371.3 & 292.1 & 266.5 & 487.1 \\
\hline Rs $(\Omega)$ & 79.2 & 88.6 & 97.6 & 183.4 \\
\hline C $(\mathrm{F})$ & $5.32 \times 10^{-5}$ & $6.53 \times 10^{-5}$ & $4.62 \times 10^{-4}$ & $5.32 \times 10^{-7}$ \\
\hline
\end{tabular}

\subsection{Effect of the OBDCs on the electricity generation performance}

Fig. 2 (a) displays the output voltages of MFCs at the various OBDCs concentrations, according to which the adaptation period of the substrate on microorganisms remained mostly the same after starting up. This might attribute to successful microbial inoculation and the thicker biofilm that was enriched on the anode (Shojaei \&Khazaee 2021, Zhang et al. 2020a). In all the examined MFCs, the output voltage at $2 \mathrm{~g} / \mathrm{L}$ 
remained approximately $525 \mathrm{mV}$ after the option on the 10th day and decreased only minimally (was relatively stable). These results demonstrated that low concentrations of OBDCs substantially affected the substrate supply and have further enhanced the growth rate of electrogenic bacteria biofilm on the anode surface (Rossi et al. 2020). A high concentration of OBDCs (>2 g/L) had a significant inhibitory effect and resulted in a decline in MFC performance, which might have been due to the high toxicity of the elements in OBDCs to microorganisms.

As shown in Fig. 2 (b), the OCV reached $752 \mathrm{mV}$ from the electrochemical polarization region due to the modification of OBDCs, compared to $651 \mathrm{mV}$ in the control group. The maximum power densities were 274, $377,530,283$ and $210 \mathrm{~mW} / \mathrm{m}^{2}$ for the control group and with the groups of OBDCs concentrations $1 \mathrm{~g} / \mathrm{L}, 2$ $\mathrm{g} / \mathrm{L}, 4 \mathrm{~g} / \mathrm{L}$, and $6 \mathrm{~g} / \mathrm{L}$, respectively. The power density did not increase with the OBDCs concentration ( $>2$ $\mathrm{g} / \mathrm{L}$ ). This was attributed to the following: 1) Some electroactive bacteria did not favor the acclimation of microorganisms when excessive OBDCs provided a new environment; 2) The electrochemically active bacteria that were shed from the biofilm surface were replaced with a mixture of OBDS and OBDCs medium that flowed through the biofilm surface.

The polarization and EIS are depicted in Fig. 2 (c) and Fig. 2 (d), respectively. It was demonstrated that the internal resistance increased initially and subsequently decreased with increasing OBDCs concentration, and the values were $601,506,519,612$ and $577 \Omega$, respectively. The total internal resistance of an MFC is a function of the sum of Rct (including the anode and cathode) and Rs. The EIS results demonstrated the effects of OBDCs attachment and biofilm formation on the Rct and Rs values of the MFCs, and the corresponding fitted values are presented in Tab. 2 . The spectral shapes of the whole cells changed with the incorporation of OBDCs. The straight line in the low frequency region extends significantly under the condition of $6 \mathrm{~g} / \mathrm{L}$ OBDCs (the equivalent circuit diagram under this condition differed significantly from those of other MFCs), which unambiguously demonstrated that charge-transport kinetic interaction between the electrode and electrolyte slows due to the the ore from a high concentration of OBDCs, thereby leading to adverse effects on the conductivity of extracellular electrons. Additionally, a maximal current density of 2.66

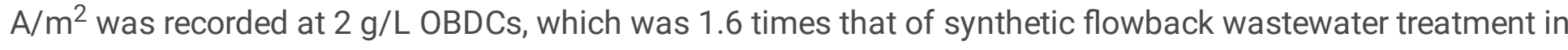
air cathode MFCs (under the same external resistance) as measured by Yang et al. (Yang et al. 2020a). This further demonstrated that the activity of electricity-producing microorganisms was the highest, and the oxidation decomposition rate of organic matter may have been the fastest at $2 \mathrm{~g} / \mathrm{L}$. As elucidated in this study, the selection of suitable SR and OBDCs concentration values could substantially promote the electrocatalysis process for the treatment of OBDS.

Tab. 2 Fitting parameters value in EIS with different OBDCs. 


\begin{tabular}{|llllll|}
\hline & Control group & $1 \mathrm{~g} / \mathrm{L}$ & $2 \mathrm{~g} / \mathrm{L}$ & $4 \mathrm{~g} / \mathrm{L}$ & $6 \mathrm{~g} / \mathrm{L}$ \\
\hline Rct $(\Omega)$ & 371.3 & 400.2 & 291.4 & 348.6 & 416.9 \\
\hline Rs $(\Omega)$ & 79.2 & 88.6 & 110.5 & 207.6 & 225.5 \\
\hline C $(\mathrm{F})$ & $5.32 \times 10^{-5}$ & $6.53 \times 10^{-5}$ & $4.62 \times 10^{-4}$ & $5.32 \times 10^{-7}$ & $/$ \\
\hline CPE-T(F) & $/$ & $/$ & $/$ & $/$ & $1.98 \times 10^{-5}$ \\
\hline CPE-P & $/$ & $/$ & $/$ & $/$ & 0.75 \\
\hline
\end{tabular}

\subsection{Effects of combining SR and OBDCs on the electricity generation and substrate removal}

The maximum power density and overall internal resistance under the optimized conditions were obtained from the power density curve and the slope of polarization (Fig. 3), which were $671 \mathrm{~mW} / \mathrm{m}^{2}\left(5.4 \mathrm{~kW} \mathrm{~h} / \mathrm{m}^{2}\right)$ and $406 \Omega$, respectively. Notably, the power density under optimized condition was 2.4 times that of control group that demonstrated that higher microbial electricity production performance when the SR and OBDCs were applied simultaneously. The output voltage curves (Fig. S2 (a)) and EIS (Fig. S2 (b)) further implied that there was satisfactory synergy between SR and the OBDCs compared with SR or the OBDCs concentration used separately.

The removal rate of COD is a key objective for wastewater treatment, has already been realized in various studies. The COD removal rate in the substrate and coulombic efficiency (CE) are shown in Fig. 4 (a). Throughout the study, the COD removal rate substantially exceeded those of other reactors, which reached $52.3 \pm 1.9 \%$ (the removal quality was $12081 \pm 432 \mathrm{mg} / \mathrm{L}$ ) after running continuously for 55 days under the synchronized condition of SR and OBDCs $(100 \mathrm{r} / \mathrm{min}+2 \mathrm{~g} / \mathrm{L})$. This was similar to the effect of palm oil treatment by the combined system that was constructed from an MFC and an anaerobic membrane microorganism reactor (Tan et al. 2017). However, the removal rate of COD did not decrease with OBDCs supplementation. The presence of oil in the anolyte helped decrease the external resistance and further facilitated increases in the electron transfer rates and redox kinetics, thereby influencing the anodic electrogenic and dehydrogenase enzyme activities. This may be due to the synergistic and antagonistic effects among the bacterial mixture of anaerobic electrogenic bacteria and excessive amounts of nonelectric-producing bacteria ( $X \mathrm{u}$ et al. 2020). The average CE under the condition of $100 \mathrm{r} / \mathrm{min}+2 \mathrm{~g} / \mathrm{L}$ was $34.7 \%$, which was substantially higher than those of other MFCs, which might be due to the realization of the fastest oxygen reduction kinetics under this case (Zhuang et al. 2020). The microorganisms were considered to be in the logarithmic phase when the stable power output was in the operation period. The degradation kinetics of the substrate were related to the mass concentration, therefore, the zero-, first- and second-order dynamic models could be used to describe the fluidized MFC (Fig. S3). According to a comparison of the three types of fitting results, the first-order kinetic model was highly suitable.

The degradation performance in the continuous mode of MFCs on $\mathrm{NH}_{3}-\mathrm{N}$ over time is shown in Fig. 4 (b), which was inconsistent with the $\mathrm{COD}$ removal. $\mathrm{NH}_{3}-\mathrm{N}$ removal gradually increased in the first 20 days and reached $74.5 \pm 0.24 \%$ in $100 \mathrm{r} / \mathrm{min}+2 \mathrm{~g} / \mathrm{L}$ group. It might ascribed to the $\mathrm{H}^{+}$migrate resulting in the rise of the $\mathrm{pH}$ value, then the concentration of volatile free ammonium was rapidly increased in the living 
environment. Additionally, some of these bacteria permeated into the cathode chamber under the driving force of the internal electric field (Jadhav \&Ghangrekar 2015). This possibility was supported by the initial removal rate of $\mathrm{NH}_{3}-\mathrm{N}$ (within 20 days) from the cathode chamber (Fig. S4 (a)). However, as diffuses to the cathode area as an electron acceptor, nitrifying bacteria may drive nitrification reactions according to Eq. (1) and Eq. (2). The functional microbial community of the anode biofilm was analyzed through high-throughput sequencing, and the power generation characteristics, organic degradation, 16S rRNA and transformation pathways of nitrogen were further discussed in Section 3.5.

The effluent concentrations of and in the anode chamber for the four cases are plotted as functions of the running time in Fig. 4 (c) and Fig. 4 (d). The removal rate reached $31.7 \pm 1.28 \%, 34.0 \pm 1.13 \%, 39.6 \pm 1.39 \%$, and $37.2 \pm 1.09 \%$ in the four anode chambers, which suggested that anaerobic environmental and carbon sources for heterotrophic denitrifying bacteria were provided by the large-capacity reaction apparatus. Moreover, nitrate is also a common electron acceptor or oxidant in bioelectrochemical systems, and the conversion of ammonium to nitrite and nitrate increased, thereby resulting in accumulation in the anode chamber and the peak concentrations of $2.35 \pm 0.018,2.4 \pm 0.025,2.65 \pm 0.022$ and $2.62 \pm 0.024 \mathrm{mg} / \mathrm{L}$, respectively, being reached on the 11th day. After the migration rate and denitrification gradually increased, a higher positive removal rate was observed under the action of infiltration. The mechanism of nitrogen, especially its removal through various reactions, can be expressed as Eq. (3) and Eq. (4). Fig. S4 (b) and Fig. S4 (c) suggest that the denitrification reaction of the biological cathode was positively correlated with the metabolic activity of the microorganisms. Although the levels of and in the anode chamber showed no significant changes in trend, the total inorganic nitrogen (TIN) content decreased by $58.9 \pm 0.2 \%$. In summary, this study has realized the objective of treating waste with waste (aged landfill leachate).

$$
\begin{aligned}
& 2 \mathrm{NH}_{4}^{+}+3 \mathrm{O}_{2} \rightarrow 2 \mathrm{NO}_{2}^{-}+4 \mathrm{H}^{+}+2 \mathrm{H}_{2} \mathrm{O} \\
& 2 \mathrm{NO}_{2}^{-}+\mathrm{O}_{2} \rightarrow 2 \mathrm{NO}_{3}^{-} \\
& \mathrm{NO}_{3}^{-}+2 \mathrm{H}^{+}+2 e^{-} \rightarrow \mathrm{NO}_{2}^{-}+\mathrm{H}_{2} \mathrm{O} \\
& 2 \mathrm{NO}_{2}^{-}+8 \mathrm{H}^{+}+6 e^{-} \rightarrow \mathrm{N}_{2}+4 \mathrm{H}_{2} \mathrm{O}
\end{aligned}
$$

\subsection{Electrochemical analysis}

To further analyze the electrochemical performances of the 4 MFC systems, CV was measured for the bioanode as the working electrode (Fig. 5(a)). It was clearly demonstrated that there are significant but differently defined oxidation peaks under the conditions of $100 \mathrm{r} / \mathrm{min}$ and optimization based on the scanned electrochemical signals; hence, the electrochemical activity is higher and the mature membrane is of higher quality compared to those of the other 2 MFCs. Moreover, the MFC at $100 \mathrm{r} / \mathrm{min}+2 \mathrm{~g} / \mathrm{L}$ showed the highest oxidation peak current $\left(i_{P}=0.3564 \mathrm{~A}\right)$, which indicates better ion diffusion and lower resistance in the coated electrode during electrochemical characterization. The peak potential was significantly shifted to the left; thus, the electrode surface required less overpotential to degrade organic matter, and the corresponding system realized a better ion diffusion effect than the systems of the other groups. Fig. 5 (b) displays the CV results at various scan rates in the optimization process. The oxidation peak currents increased, and a shift 
in the oxidation peak potential to the right was observed as the scan rate increased. This result may be interpreted as the enhancement of the ion interfacial polarization phenomenon of the electrolyte at higher scan rates; however, the change in the integral area of the curve suggested that the effect on the electrode interfacial dynamics for electrochemical charge storage or capacitance was ignored (Kumbhar et al. 2020).

Linear fitting was conducted for ip with respect to the scan rate $(V)$ and its square root $\left(V^{1 / 2}\right)$, and the fitting results are shown in Fig. 5 (c), where the correlation coefficient of the former $\left(R^{2}=0.92\right)$ was less than that of the latter $\left(R^{2}=0.98\right)$, which indicated that diffusion control was the dominant position and adsorption control was the non-dominant position. The value of the diffusion control constant $(\mathrm{k})$ reflected the substantial catalytic oxidation-reduction reaction (ORR) and electrochemical performance of the electrode compared with a previous study (Jiang et al. 2020). This improvement was attributed to the formation of stable biofilms on the electrode surface at the end of operation.

The Tafel curve is a positive tool to evaluate activation loss in redox reactions. Fig. 5 (d) shows the Tafel plots of the cathode as the working electrode. The exchange potential, current and Tafel slope of the anode and cathode can be obtained by fitting the linear interval of the Tafel curve (Tab. S3). The MFC electrode $(100 \mathrm{r} / \mathrm{min}+2 \mathrm{~g} / \mathrm{L})$ exhibited a Tafel slope of $43.2 \mathrm{mV} / \mathrm{dec}$, which was smaller than those of the control group $(112.3 \mathrm{mV} / \mathrm{dec})$ and the $100 \mathrm{r} / \mathrm{min}(54.1 \mathrm{mV} / \mathrm{dec})$ and $2 \mathrm{~g} / \mathrm{L}(51.3 \mathrm{mV} / \mathrm{dec})$ groups. This result demonstrated the excellent redox catalytic activity and improved kinetics under the $100 \mathrm{r} / \mathrm{min}+2 \mathrm{~g} / \mathrm{L}$ condition. The exchange potential of the $100 \mathrm{r} / \mathrm{min}+2 \mathrm{~g} / \mathrm{L}$ bioanode was $380 \mathrm{mV}$, which was shifted to the right by $93 \mathrm{mV}$ relative to the control group $(287 \mathrm{mV})$; hence, the biological anode had higher thermodynamic stability and responded faster to potential changes [45]. The Tafel results were found to be in substantial agreement with the EIS and CV results.

\subsection{Composition of the microbial community}

DNA was extracted from the anode biofilms of the control group and the groups with conditions of 100 $\mathrm{r} / \mathrm{min}, 2 \mathrm{~g} / \mathrm{L}$ and $2 \mathrm{~g} / \mathrm{L}+100 \mathrm{r} / \mathrm{min}$, and the genetic composition of the $\mathrm{V} 3$ to $\mathrm{V} 4$ regions of $16 \mathrm{~S}$ rRNA was analyzed to determine the microbial community composition.

The 16S rRNA gene clone library analysis information is presented in Tab. 3, which showed that more than 363350 valid sequences were obtained in each sample, and more than 54000 sequences were identified under $100 \mathrm{r} / \mathrm{min}+2 \mathrm{~g} / \mathrm{L}$. The number of sequences that were selected randomly from each sample and the number of operational taxonomic units (OTUs) that were represented by these sequences were used to construct rarefaction curves, as shown in Fig. S5, which demonstrated that the sequencing process was suitable and highly credible (Zhang et al. 2020c).

Tab. 3 Information of 16S rRNA gene clone library analysis 


\begin{tabular}{|llllllll|}
\hline Sample\Estimators & sequence & Ace $^{1}$ & chao $^{1}$ & coverage $^{2}$ & Shannon $^{2}$ & Simpson $^{3}$ & sobs \\
\hline control group & 36,335 & 176.85 & 164.44 & 0.999 & 2.85 & 0.08 & 142.00 \\
\hline $100 \mathrm{r} / \mathrm{min}$ & 53,632 & 937.83 & 925.27 & 0.998 & 2.65 & 0.37 & 904.00 \\
\hline $2 \mathrm{~g} / \mathrm{L}$ & 41,467 & 451.11 & 470.32 & 0.998 & 3.43 & 0.06 & 339.00 \\
\hline $100 \mathrm{r} / \mathrm{min}+2 \mathrm{~g} / \mathrm{L}$ & 54,096 & 1011.97 & 998.12 & 0.998 & 5.06 & 0.02 & 945.00 \\
\hline
\end{tabular}

${ }^{1}$ The community abundance is directly proportional to the value

${ }^{2}$ The community diversity is directly proportional to the value

${ }^{3}$ The community diversity is inversely proportional to the value

Fig. 6 (a) shows the analysis of the microbial community structure at the phylum level. The most abundant microflora in the anode biofilms were Proteobacteria and Bacteroides after the operation of MFCs (their sum reached more than $61 \%$ ), which are two types of important electricity-producing and organic compounddegrading bacteria that can perform long-distance electronic transmission. The abundance of Actinobacteria in the $100 \mathrm{r} / \mathrm{min}, 2 \mathrm{~g} / \mathrm{L}$ and $100 \mathrm{r} / \mathrm{min}+2 \mathrm{~g} / \mathrm{L}$ groups was increased significantly compared with that in the control group, which suggested that the synergy of OBDCs and stirring with rate SR enhanced the leading role of sulfur-reducing and nitrate-denitrifying bacteria. This might demonstrate the effects of simultaneous inorganic nitrogen and organic loads on the growth of autotrophic and heterotrophic bacteria. Meanwhile, other phyla, namely, Chloroflexi and Firmicutes, accumulated in the anode, which contributed to the electric acclimation and selection of oil-based microbes and anode microbial communities, and they were likely conducive to the removal of complex organic matter, such as anionic polyacrylamide (Zhang et al. 2018a).

To further identify the dominant microbial communities in the anodic biofilms of all systems, a contrast experiment at the family level was conducted. As shown in Fig. 6 (b), the predominant bacteria were Gammaproteobacteria, Alphaproteobacteria and Bacteroidia, all of which belong to the phyla Proteobacteria and Bacteroidetes. These bacteria have been reported to include many active electrogenic microorganisms, which can transfer electrons efficiently from electroactive bacteria to electrodes through electron transfer shuttles, such as cytochrome C, to increase the energy output (Xin \&Qiu 2021, Zhang et al. 2020a). Moreover, Actinobacteria was highly enriched after the application of OBDCs, and its abundance reached $20 \%$ and $10 \%$ at $2 \mathrm{~g} / \mathrm{L}$ and $100 \mathrm{r} / \mathrm{min}+2 \mathrm{~g} / \mathrm{L}$, respectively. This type of bacteria not only plays an important role in the process of anode EET but also can metabolize a variety of carbohydrates and produce intermediate products such as lactic acid, acetic acid and formic acid, thereby providing nutrients for other heterotrophic bacteria, such as the abundance of facultative anaerobic denitrifying bacteria Bacilli and Anaerolineae increased significantly after imposing suitable mixing rate or solid particle conditions (which reached approximately $5 \%$ and $4 \%$, and $11 \%$ and $6 \%$, respectively). Thus, the systems further inhibited the presence of dissolved oxygen and leading to nitrate deoxidized to nitrites and nitrogen in long-term operation (Zhang et al. 2020b). However, the two types of families slightly decreased in abundance in the $100 \mathrm{r} / \mathrm{min}+2 \mathrm{~g} / \mathrm{L} \mathrm{complex}$ environment, which indicated that they may be electricigen-resistant or undergo electric acclimation and selection (Chaturvedi et al. 2021, Yu et al. 2021). 
These findings suggested that the control group differed from the other groups and that the synergistic effects of multiple functional microorganisms played a vital catalytic role in the simultaneous contaminant degradation and bioelectricity generation. Therefore, the dominant microorganisms in various samples should be further analyzed. A heatmap was constructed of 30 genera with the most abundant species (Fig. 6 (c)), which represented the community composition differences in sequences and changes in relative richness by different colors. The results demonstrated that Pseudomonas, Rhodopseudomonas, Burkholderiaceae, Comamonas, Sphingopyxis, Nocardia, Gelidibacter, Weeksellaceae and Thermomonas successfully thrived under the $100 \mathrm{r} / \mathrm{min}+2 \mathrm{~g} / \mathrm{L}$ condition. Some bacteria (Pseudomonas, Acidovorax, Burkholderiaceae and Comamonas) have been reported to be typical electrogenic bacteria with extracellular electron transfer functions for sulfide oxidation in MFC systems (Commault et al. 2015).

Rhodopseudomonas performed autotrophic denitrification under the anaerobic environment, in which using the sodium thiosulfate and hydrogen sulfide as electron donors, but there was almost no development of them in the group of $100 \mathrm{r} / \mathrm{min}$. Hence, the heatmap indicated that various dominating factors causing the gathering of electroactive microorganisms, such as inorganic mineral composition of OBDCs might influence the bacterial community structure in the local environment. The sample cluster analysis (on the top of the heatmap) from Fig. 6 (c) compared the genera in terms of diversity, which clearly showed that the electrode biofilms of the control group and the $100 \mathrm{r} /$ min group were similar but differed completely from those of the last two groups. Thus, agitation and OBDCs have important effects on microbial abundance and diversity, respectively. As discussed in a previous study (Yang et al. 2019), microorganisms from different environments may exhibit differences in terms of microbial metabolism and eventually influence the electricity production performance and pollutants in wastewater removal mechanisms.

The results of principal coordinate analysis (PCA) were presented in Fig. 7, which suggested that the differences in the above microbial communities in the 4 samples were based on the two leading factors, namely, PC1 and PC2, and the corresponding dominant components of both sides were $80.55 \%$ and $14 \%$, which accounted for $94.55 \%$ of the changes that were identified among the microbial communities. Samples 1 and 2 were well separated from each other by long distances in the PC1 direction. According to the heatmap, the introduction of SR and OBDCs into MFCs would supply sufficient electronic receptors for stimulate electricigens growth and enrichment on the anode, and further improve the species richness and abundance of the microbial community. From the shorter distance between sample 3 and sample 4 in PC1 and PC2, it was concluded that the electrode was well inoculated initially and that a rough surface was beneficial for the electric acclimation of indigenous electricigens in OBDCs and their enrichment.

\subsection{Biofilm and substrate characterization}

The SEM morphologies of the control group and $100 \mathrm{r} / \mathrm{min}+2 \mathrm{~g} / \mathrm{L}$ anode biofilms were identified to compare the effects of the two key factors on the morphology and viability at the end of operation (Fig. 8 (a) (f)). Nonabundant and nonhomogeneous bacterial growth was observed on the anode surface from control group (Fig. 8 (a) and Fig. 8 (b)); however, high-colored flocculate attachment (possibly due to the microbial metabolites and extracellular polymers) was observed on the $100 \mathrm{r} / \mathrm{min}+2 \mathrm{~g} / \mathrm{L} \mathrm{MFCs}$, which was consistent with the results of a previous study by Şeyho Topcu (Topcu \&Taskan 2020). Fig. 8 (d) and Fig. 8 (f) shows biofilms with larger specific surface areas and overlapping denser structures compared to Fig. 8 (c) and Fig. 
8 (e). This resulted from the contact area between microorganisms and petroleum hydrocarbons increasing in these cases, which provided better conditions for the adsorption and growth of microorganisms through the removal of the complex decomposition process or metal ion reduction.

EDS measurement also supported the presence of element species on the anode under operation in a closed circuit (Fig. 8 (g) and Fig. 8 (h)). Thus, the biofilm after domestication may be a type of biochar that contained $\mathrm{C}, \mathrm{N}$, and $\mathrm{O}$, thereby implying the presence of bacteria with high electrocatalytic oxidation activity (Zhang et al. 2018b). Element mapping (Fig. S6 (a) and Fig. S6 (b)) further supported this finding. Quantitative results regarding the elemental compositions of the biofilms that are based on EDS spectra are presented in Tab. S4. Excluding elements $\mathrm{C}, \mathrm{N}$, and $\mathrm{O}$, most metallic crystals of $\mathrm{Fe}, \mathrm{Ca}$, and $\mathrm{Al}$ and metalloids Si and S were observed in the $100 \mathrm{r} / \mathrm{min}+2 \mathrm{~g} / \mathrm{L} \mathrm{MFC}$, which represented more than $13 \%$ (atomic percentage) and might attributed to oxides, sulfates, or chlorides of sodium and potassium. Similar results for the elemental compositions of biofilms have been reported in a previous study (Rambabu et al. 2021).

FT-IR changes in the substrate before versus after treatment at $100 \mathrm{r} / \mathrm{min}+2 \mathrm{~g} / \mathrm{L}$ are shown in Fig. 9 (a). Various bands were sensitive to the states of the crystalline and amorphous regions of the substrate, such as the bands at $3443 \mathrm{~cm}^{-1}, 1632 \mathrm{~cm}^{-1}$, and $465 \mathrm{~cm}^{-1}$ of the substrate in untreated samples and at the end of operation, thereby suggesting the possible presence of a hydroxyl group $-\mathrm{NH}_{2}$ band (Paswan \&Mahto 2020) and stretching vibrations of $\mathrm{C}=\mathrm{C}$ and $\mathrm{S}-\mathrm{O}$ of the sulfonate group, respectively (Wang et al. 2019). According to the changes in the peak strength and area at $3443 \mathrm{~cm}^{-1}$, the amount of organic matter with nitrogencontaining functional groups in the substrates decreased significantly, but no other intermediates were produced, and a similar scenario was observed at $3400 \mathrm{~cm}^{-1}$ in the control group (Fig. S7 (a)). In addition, the absorption bands from the untreated substrate have wavenumbers of $1092 \mathrm{~cm}^{-1}$ and $787 \mathrm{~cm}^{-1}$, which were ascribed to quartz, as previously reported (Yang et al. 2020b). Furthermore, the two peaks shifted to $1180 \mathrm{~cm}^{-}$ 1 and $613 \mathrm{~cm}^{-1}$, thereby indicating a close interaction between the functional groups of organic matter and metal (Francis Prashanth et al. 2021).

The phase composition and structural changes of untreated and treated substrates were identified via XRD (Fig. 9 (b)). The differences in the peaks between the treated and untreated samples demonstrated that the crystalline structures differed significantly, which showed the same trend as the FT-IR results. Two main diffraction peaks with narrow widths were observed at $2 \theta=26.8^{\circ}$ and $28.1^{\circ}$, which supported a strong crystalline structure $\left(\mathrm{C}_{13} \mathrm{~N}_{9} \mathrm{NH}_{3} \mathrm{PO}_{4}\right)$ existence before and after treatment, respectively, and the peak crystallinity intensity decreased significantly, which clearly suggested organic matter from OBDS might degradation and partly larger particles converted to smaller particles. However, the peak of $\mathrm{C}_{13} \mathrm{~N}_{9} \mathrm{NH}_{3} \mathrm{PO}_{4}$ didn't decreased at the end of the running in the control group (Fig. S7 (b)), which further revealed that the reason for lower COD removal rate in this case compared to $100 \mathrm{r} / \mathrm{min}+2 \mathrm{~g} / \mathrm{L}$. $\mathrm{BaSO}_{4}$ was identified as the main component and used as the weight agent in the OBDS and OBDCs (Chen et al. 2018), and the peaks of this crystalline structure has no obvious change in this study. Additionally, diffraction peaks of other crystal phases and microstructures were detected in the substrates such as $\mathrm{SiO}_{2}, \mathrm{CaCO}_{3}$ and $\mathrm{MgCO}_{3}$. The EDS results of substrates from the control group and group with $100 \mathrm{r} / \mathrm{min}+2 \mathrm{~g} / \mathrm{L}$ (Fig. S8 and Tab. S5) further supported the presence of above compounds. From another viewpoint, the atomic percentage of Si element 
in the group of $100 \mathrm{r} / \mathrm{min}+2 \mathrm{~g} / \mathrm{L}$ was increased by $13.43 \%$ compared with the control group. Previous research has shown that the power density can be improved approximately 15 -fold by adding appropriate amount of $\mathrm{SiO}_{2}$ (Cheraghipoor et al. 2021). It is proved that $\mathrm{SiO}_{2}$ of OBDCs plays a crucial role in improving the performance of MFC. By contrast, the atomic percentage of S element decreased $5.46 \%$ from the group of $100 \mathrm{r} / \mathrm{min}+2 \mathrm{~g} / \mathrm{L}$ to control group that further indicated the element might involve in the denitrification process.

Based on these results and those of earlier studies (Feng et al. 2020, Li et al. 2021, Yellappa et al. 2020), a main schematic diagram and possible mechanisms of the simultaneous removal of complex organics and nitrogen from OBDS by the MFC were proposed, as presented in Fig. 10. In the anode chamber, the following reactions can be inferred: (1) an electrochemical reaction in which electroactive microorganisms (Proteobacteria and Bacteroides, among others) degrade organic matter to small molecules and simultaneously acquire electrons for EET; (2) heterotrophic denitrification, in which organic matters is utilized

as an electron donor and nitrate is deoxidized to nitrites and nitrogen; and (3) autotrophic denitrification, in which the sulfide acts as an electron donor.

\section{Conclusions}

This study demonstrated the application of SR and OBDCs in an anode chamber for MFC treated OBDS to increase the microbial diversity and relative abundance (extracellular electron transfer function) while improving the electrocatalytic oxidation properties. The maximum power density $\left(671 \mathrm{~mW} / \mathrm{m}^{2}\right)$ and minimum internal resistance (406 $\Omega$ ) were realized in the optimization process, and the COD removal rate was reached $52.3 \pm 1.9 \%$ simultaneously. Based on the substrate removal and microbial community analysis, the positive effects of SR and OBDCs were attributed to the promotion of the growth of anaerobes that were involved with electrogenic bacteria, and denitrifying bacteria. In addition, the degradation process of organic matters and nitrogen was suggested through microbial community analysis and substrate characterization. Current work provided a strategy for electrochemically active bacteria enrichment in MFCs and a new energy-saving approach for the disposal of wastewater and waste from oil and gas.

\section{Abbreviations}

OBDCs, oil based drill cuttings; OBDS, oil based drill sludge; SR, stirring rate; MFC(s), microbial fuel cell(s); TIN, total inorganic nitrogen; ORR, oxidation-reduction reaction; COD, chemical oxygen demand; EET, extracellular electron transfer; SRs, stirring rates; FT-IR fourier transform infrared spectrometer; $X$ ray diffraction, XRD; PEM, proton exchange membrane; OCV, open circuit voltage; CV, cyclic voltammetry; EIS, electrochemical impedance spectroscopy; SEM, scanning electron microscopy; EDS, energy dispersive spectrometer; $\mathrm{CE}$, coulombic efficiency; Rct, charge transfer resistance; Rs, solution resistance; $\mathrm{CPE}$, constant phase element; PCA, principal component analysis; OTUs, operational taxonomic units.

\section{Declarations}


Authors' contributions: Qi Feng: Conceptualization, Methodology, Software, Investigation, Writing-Original Draft; Longjun Xu: Review \& Editing, Supervision, Validation, Formal analysis, Visualization; Chenglun Liu: Validation, Formal analysis, Visualization; Yu Hao: Resources, Writing - Review \& Editing, Data Curation; Zhengxin Yang: Resources, Writing-Review \& Editing, Supervision; Teng Zhang: Data Curation, Writing: Review \& Editing; Yanling Liu: Writing: Review \& Editing; Huaren Su: Writing: Review \& Editing.

Fundings: This work was supported by the independent research project of State Key Laboratory of Coal Mine Disaster Dynamics and Control (2011DA105287-zd201904), Innovative Talents Training Program for Chongqing Primary and Secondary School Students (CY200148) and National Key Research and Development Project (2019YFC1805500).

Data availability: The datasets used and/or analyzed during the current study are available from the corresponding author on reasonable request.

\section{Compliance with ethical standards}

Competing interests: The authors claim that there are no conflicts of interest.

Ethical approval and consent to participate: Not applicable.

Consent to publication: Not applicable.

\section{Appendix. Supplementary data}

Supplementary data can be found on supplementary material.

\section{References}

Chaturvedi P, Giri BS, Shukla P, Gupta P (2021): Recent advancement in remediation of synthetic organic antibiotics from environmental matrices: Challenges and perspective. Bioresour Technol 319, 124161

Chen S, Patil SA, Brown RK, Schröder U (2019): Strategies for optimizing the power output of microbial fuel cells: Transitioning from fundamental studies to practical implementation. Applied Energy $233-234,15-28$

Chen Z, Zhou J, Chen Z, Chen H, Chen Q, He C, Liu X, Yuanjian X (2018): A laboratory evaluation of superheated steam extraction process for decontamination of oil-based drill cuttings. Journal of Environmental Chemical Engineering 6, 6691-6699

Chen Z, Zheng Z, Li D, Chen H, Xu Y (2020): Continuous supercritical water oxidation treatment of oil-based drill cuttings using municipal sewage sludge as diluent. J Hazard Mater 384, 121225

Cheraghipoor M, Mohebbi-Kalhori D, Noroozifar M, Maghsoodlou MT (2021): Production of greener energy in microbial fuel cell with ceramic separator fabricated using native soils: Effect of lattice and porous SiO2. Fuel 284, 118938 
Chiranjeevi P, Patil SA (2020): Strategies for improving the electroactivity and specific metabolic functionality of microorganisms for various microbial electrochemical technologies. Biotechnol Adv 39, 107468

Commault AS, Barriere F, Lapinsonniere L, Lear G, Bouvier S, Weld RJ (2015): Influence of inoculum and anode surface properties on the selection of Geobacter-dominated biofilms. Bioresour Technol 195, 265-72

Feng Q, Xu L, Liu C, Wang H, Jiang Z, Xie Z, Liu Y, Yang Z, Qin Y (2020): Treatment of shale gas fracturing wastewater using microbial fuel cells: Mixture of aging landfill leachate and traditional aerobic sludge as catholyte. Journal of Cleaner Production 269, 121776

Francis Prashanth P, Shravani B, Vinu R, M L, Ramesh Prabu V (2021): Production of diesel range hydrocarbons from crude oil sludge via microwave-assisted pyrolysis and catalytic upgradation. Process Safety and Environmental Protection 146, 383-395

Gao L, Thangavel S, Guo Z-C, Cui M-H, Wang L, Wang A-J, Liu W-Z (2019): Hydrodynamics Analysis for an Upflow Integrated Anaerobic Digestion Reactor with Microbial Electrolysis under Different Hydraulic Retention Times: Effect of Bioelectrode Spatial Distribution on Functional Communities Involved in Methane Production and Organic Removal. ACS Sustainable Chemistry \& Engineering 8, 190-199

Gonzalez T, Puigagut J, Vidal G (2021): Organic matter removal and nitrogen transformation by a constructed wetland-microbial fuel cell system with simultaneous bioelectricity generation. Sci Total Environ 753,142075

Hu G, Liu H, Chen C, Hou H, Li J, Hewage K, Sadiq R (2020): Low-temperature thermal desorption and secure landfill for oil-based drill cuttings management: Pollution control, human health risk, and probabilistic cost assessment. J Hazard Mater, 124570

Islam MA, Ehiraj B, Cheng CK, Dubey BN, Khan MMR (2019): Biofilm re-vitalization using hydrodynamic shear stress for stable power generation in microbial fuel cell. Journal of Electroanalytical Chemistry 844, 14-22

Jadhav DA, Ghangrekar MM (2015): Effective ammonium removal by anaerobic oxidation in microbial fuel cells. Environmental Technology 36, 767-775

Jiang L, Chen J, An Y, Han D, Chang S, Liu Y, Yang R (2020): Enhanced electrochemical performance by nickel-iron layered double hydroxides (LDH) coated on Fe304 as a cathode catalyst for single-chamber microbial fuel cells. Sci Total Environ 745, 141163

Jiaqi S, Lifen L, Fenglin Y (2020): Successful bio-electrochemical treatment of nitrogenous mariculture wastewater by enhancing nitrogen removal via synergy of algae and cathodic photo-electro-catalysis. Sci Total Environ 743, 140738

Jones AD, Buie CR (2019): Continuous shear stress alters metabolism, mass-transport, and growth in electroactive biofilms independent of surface substrate transport. Sci Rep 9, 2602 
Kumbhar VS, Lee W, Lee K (2020): Self-assembly of NiMoO4 nanoparticles on the ordered NiCo2O4 ultra-thin nanoflakes core-shell electrode for high energy density supercapacitors and efficient oxygen evolution reaction. Ceramics International 46, 22837-22845

Li H, Xing Y, Cao T, Dong J, Liang S (2021): Evaluation of the fouling potential of sludge in a membrane bioreactor integrated with microbial fuel cell. Chemosphere 262, 128405

Li Z, Yang S, Song Y, Xu H, Wang Z, Wang W, Zhao Y (2020): Performance evaluation of treating oilcontaining restaurant wastewater in microbial fuel cell using in situ graphene/polyaniline modified titanium oxide anode. Environ Technol 41, 420-429

Lin Z, Xu F, Wang L, Hu L, Zhu L, Tan J, Li Z, Zhang T (2020): Characterization of oil component and solid particle of oily sludge treated by surfactant-assisted ultrasonication. Chinese Journal of Chemical Engineering

Liu J, Vipulanandan C (2017): Effects of $\mathrm{Fe}, \mathrm{Ni}$, and $\mathrm{Fe} / \mathrm{Ni}$ metallic nanoparticles on power production and biosurfactant production from used vegetable oil in the anode chamber of a microbial fuel cell. Waste Manag 66, 169-177

Lu Z, Liu W, Bao M, Zhao L, Sun X, Lu J, Li Y (2020): Oil recovery from polymer-containing oil sludge in oilfield by thermochemical cleaning treatment. Colloids and Surfaces A: Physicochemical and Engineering Aspects, 125887

Matsumoto A, Nagoya M, Tsuchiya M, Suga K, Inohana Y, Hirose A, Yamada S, Hirano S, Ito Y, Tanaka S, Kouzuma A, Watanabe K (2020): Enhanced electricity generation in rice paddy-field microbial fuel cells supplemented with iron powders. Bioelectrochemistry 136, 107625

Nandy A, Radović JR, Novotnik B, Sharma M, Larter SR, Thangadurai V (2020): Investigation of crude oil degradation using metal oxide anode-based microbial fuel cell. Bioresource Technology Reports 11, 100449

Nor MH, Mubarak MF, Elmi H, Ibrahim N, Wahab MF, Ibrahim Z (2015): Bioelectricity generation in microbial fuel cell using natural microflora and isolated pure culture bacteria from anaerobic palm oil mill effluent sludge. Bioresour Technol 190, 458-65

Palanisamy G, Jung H-Y, Sadhasivam T, Kurkuri MD, Kim SC, Roh S-H (2019): A comprehensive review on microbial fuel cell technologies: Processes, utilization, and advanced developments in electrodes and membranes. Journal of Cleaner Production 221, 598-621

Pan Y, Zhu T, He Z (2019): Energy advantage of anode electrode rotation over anolyte recirculation for operating a tubular microbial fuel cell. Electrochemistry Communications 106, 106529

Paswan BK, Mahto V (2020): Development of environment-friendly oil-in-water emulsion based drilling fluid for shale gas formation using sunflower oil. Journal of Petroleum Science and Engineering 191, 107129 
Peng X, Yu H, Wang X, Gao N, Geng L, Ai L (2013): Enhanced anode performance of microbial fuel cells by adding nanosemiconductor goethite. Journal of Power Sources 223, 94-99

Pham HT, Boon N, Aelterman P, Clauwaert P, De Schamphelaire L, van Oostveldt P, Verbeken K, Rabaey K, Verstraete W (2008): High shear enrichment improves the performance of the anodophilic microbial consortium in a microbial fuel cell. Microb Biotechnol 1, 487-96

Pinck S, Ostormujof LM, Teychene S, Erable B (2020): Microfluidic Microbial Bioelectrochemical Systems: An Integrated Investigation Platform for a More Fundamental Understanding of Electroactive Bacterial Biofilms. Microorganisms 8

Rajaković V, Skala D (2006): Separation of water-in-oil emulsions by freeze/thaw method and microwave radiation. Separation and Purification Technology 49, 192-196

Rambabu K, Bharath G, Banat F, Show PL (2021): Green synthesis of zinc oxide nanoparticles using Phoenix dactylifera waste as bioreductant for effective dye degradation and antibacterial performance in wastewater treatment. J Hazard Mater 402, 123560

Rossi R, Pant D, Logan BE (2020): Chronoamperometry and linear sweep voltammetry reveals the adverse impact of high carbonate buffer concentrations on anode performance in microbial fuel cells. Journal of Power Sources 476, 228715

Shojaei B, Khazaee I (2021): 1-D transient microbial fuel cell simulation considering biofilm growth and temperature variation. International Journal of Thermal Sciences 162, 106801

Suchocki T, Witanowski Ł, Lampart P, Kazimierski P, Januszewicz K, Gawron B (2021): Experimental investigation of performance and emission characteristics of a miniature gas turbine supplied by blends of kerosene and waste tyre pyrolysis oil. Energy 215, 119125

Tan SP, Kong HF, Bashir MJK, Lo PK, Ho CD, Ng CA (2017): Treatment of palm oil mill effluent using combination system of microbial fuel cell and anaerobic membrane bioreactor. Bioresour Technol 245, 916924

Topcu S, Taskan E (2020): Effect of the tetracycline antibiotics on performance and microbial community of microbial fuel cell. Bioprocess Biosyst Eng

Wang C-q, Lin X-y, Mei X-d, Luo X-g (2019): Performance of non-fired bricks containing oil-based drilling cuttings pyrolysis residues of shale gas. Journal of Cleaner Production 206, 282-296

Wang CT, Li IT, Jang JH (2020): Effect of electrode spacing on the performance of microbial fuel cells with a honeycomb flow straightener. International Journal of Energy Research 44, 12136-12144

Xin X, Qiu W (2021): Linking microbial mechanism with bioelectricity production in sludge matrix-fed microbial fuel cells: Freezing/thawing liquid versus fermentation liquor. Sci Total Environ 752, 141907 
Xu C, Lu J, Zhao Z, Zhang Y, Zhang J (2020): Electricity Generation, Salt and Nitrogen Removal and Microbial Community in Aircathode Microbial Desalination Cell for Saline-Alkaline Soil-Washing Water Treatment.

Water 12, 2257

Yang F, Zhang K, Zhang D, Zhang L, Huang Y (2020a): Treatment and nutrient recovery of synthetic flowback water from shale gas extraction by air-cathode ( PMo /CB ) microbial desalination cells. Journal of Chemical Technology \& Biotechnology

Yang H, Huang S, Zhang Y, Zhou B, Manzoor Ahmed S, Liu H, Liu Y, He Y, Xia S (2020b): Remediation effect of $\mathrm{Cr}(\mathrm{VI})$-contaminated soil by secondary pyrolysis oil-based drilling cuttings ash. Chemical Engineering Journal 398, 125473

Yang N, Zhan G, Li D, Wang X, He X, Liu H (2019): Complete nitrogen removal and electricity production in Thauera-dominated air-cathode single chambered microbial fuel cell. Chemical Engineering Journal 356, 506-515

Yang Q, Wu Z, Liu L, Zhang F, Liang S (2016): Treatment of Oil Wastewater and Electricity Generation by Integrating Constructed Wetland with Microbial Fuel Cell. Materials (Basel)

Yellappa M, Annie Modestra J, Rami Reddy YV, Venkata Mohan S (2020): Functionalized conductive activated carbon-polyaniline composite anode for augmented energy recovery in microbial fuel cells. Bioresour Technol 320, 124340

Yoon JY, Ahn Y, Schröder U (2018): Parylene C-coated PDMS-based microfluidic microbial fuel cells with low oxygen permeability. Journal of Power Sources 398, 209-214

Yu B, Feng L, He Y, Yang L, Xun Y (2021): Effects of anode materials on the performance and anode microbial community of soil microbial fuel cell. J Hazard Mater 401, 123394

Zhang J, Chu L, Wang Z, Guo W, Zhang X, Zhang X, Chen R, Dong S, Sun J (2020a): Dynamic evolution of electrochemical and biological features in microbial fuel cells upon chronic exposure to increasing oxytetracycline dosage. Bioelectrochemistry 136, 107623

Zhang J, Yu P, Fan L, Sun Y (2021): Effects of ultrasound treatment on the starch properties and oil absorption of potato chips. Ultrason Sonochem 70, 105347

Zhang L, Wang J, Fu G, Zhang Z (2020b): Simultaneous electricity generation and nitrogen and carbon removal in single-chamber microbial fuel cell for high-salinity wastewater treatment. Journal of Cleaner Production 276, 123203

Zhang X, Chen A, Zhang D, Kou S, Lu P (2018a): The treatment of flowback water in a sequencing batch reactor with aerobic granular sludge: Performance and microbial community structure. Chemosphere 211, 1065-1072 
Zhang X, Zhang D, Huang Y, Wu S, Lu P (2020c): The anodic potential shaped a cryptic sulfur cycling with forming thiosulfate in a microbial fuel cell treating hydraulic fracturing flowback water. Water Res 185, 116270

Zhang Y, Li G, Wen J, Xu Y, Sun J, Ning XA, Lu X, Wang Y, Yang Z, Yuan Y (2018b): Electrochemical and microbial community responses of electrochemically active biofilms to copper ions in bioelectrochemical systems. Chemosphere 196, 377-385

Zhang Y, Li J, Yang W, Zhang J, Fu Q, Song Y-C, Wei Z, Liao Q, Zhu X (2020d): Fe-N-doped carbon nanoparticles from coal tar soot and its novel application as a high performance air-cathode catalyst for microbial fuel cells. Electrochimica Acta 363, 137177

Zhou J, Li M, Zhou W, Hu J, Long Y, Tsang YF, Zhou S (2020): Efficacy of electrode position in microbial fuel cell for simultaneous $\mathrm{Cr}(\mathrm{VI})$ reduction and bioelectricity production. Sci Total Environ 748, 141425

Zhuang S, Shao C, Ye J, Li B, Wang X (2020): Enhancing oxygen reduction reaction in air-cathode microbial fuel cells treating wastewater with cobalt and nitrogen co-doped ordered mesoporous carbon as cathode catalysts. Environ Res 191, 110195

\section{Figures}



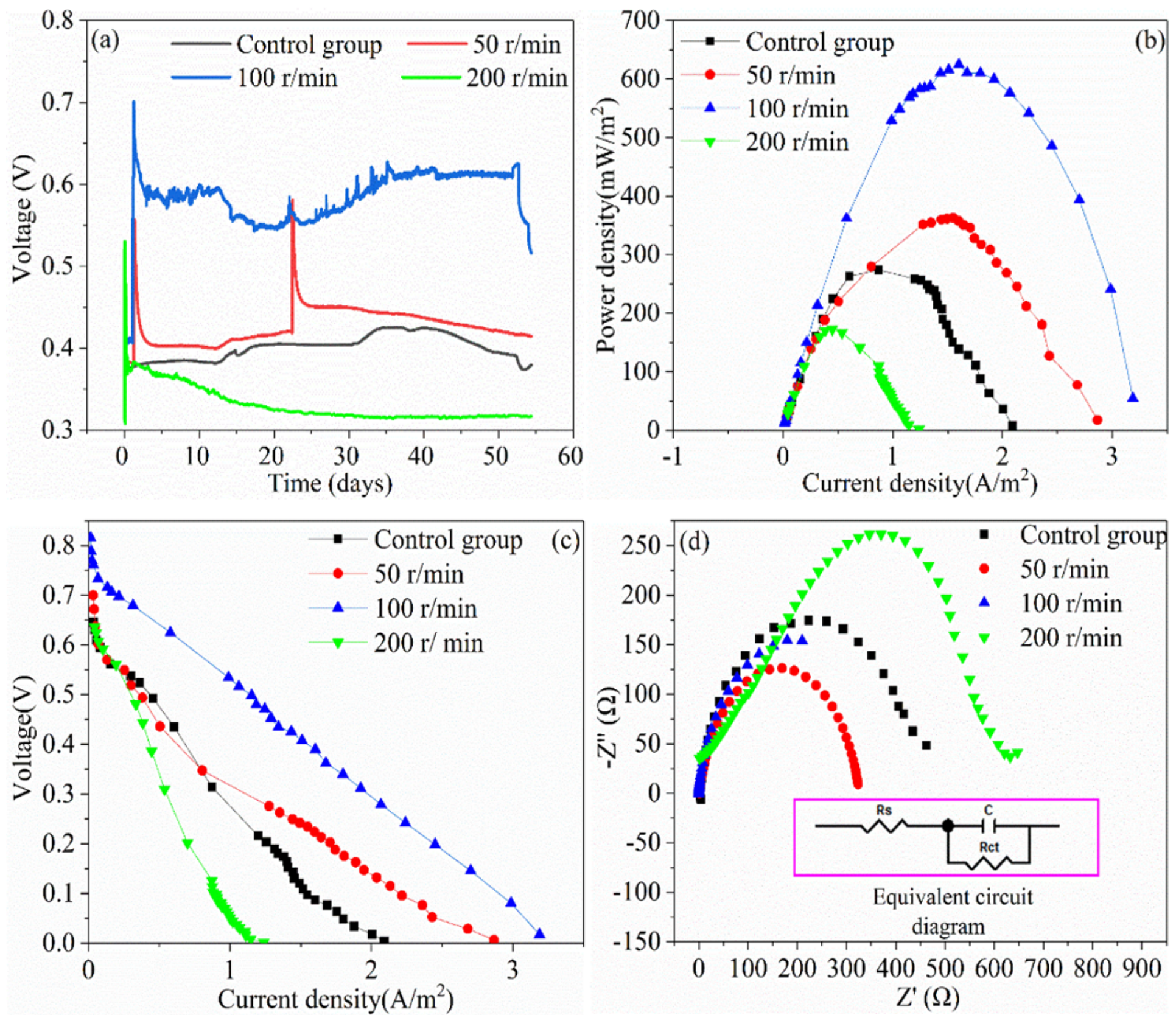

Figure 1

Performance comparison under various SRs: (a) output voltage and (b) power density curves; (c) polarization curves; and (d) EIS ( $C$ in the equivalent circuit diagram represents the double layer capacitance). 

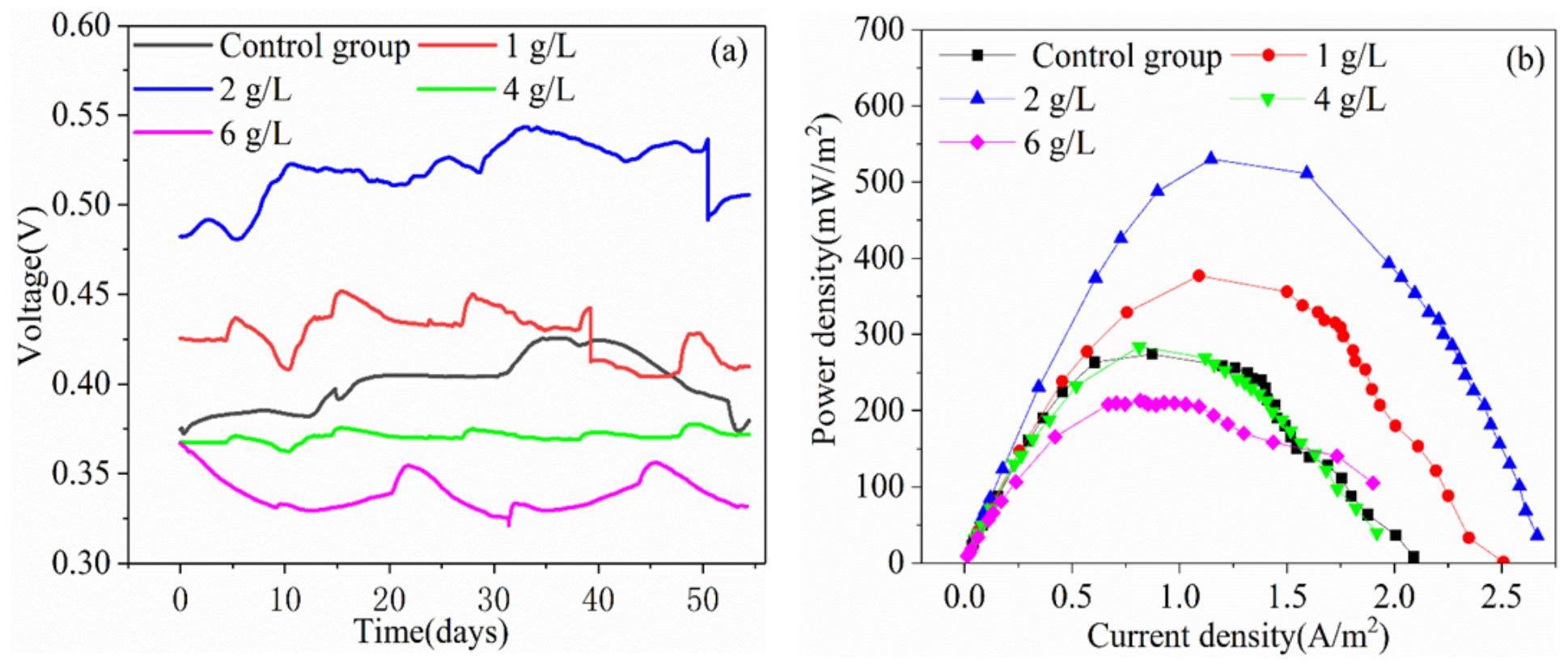

Figure 2

Performance comparison under various OBDCs concentrations: (a) output voltage curves, (b) power density curves, (c) polarization curves, and (d) EIS (the CPE in the equivalent circuit diagram represents the constant phase element that is associated with a double electrical layer).

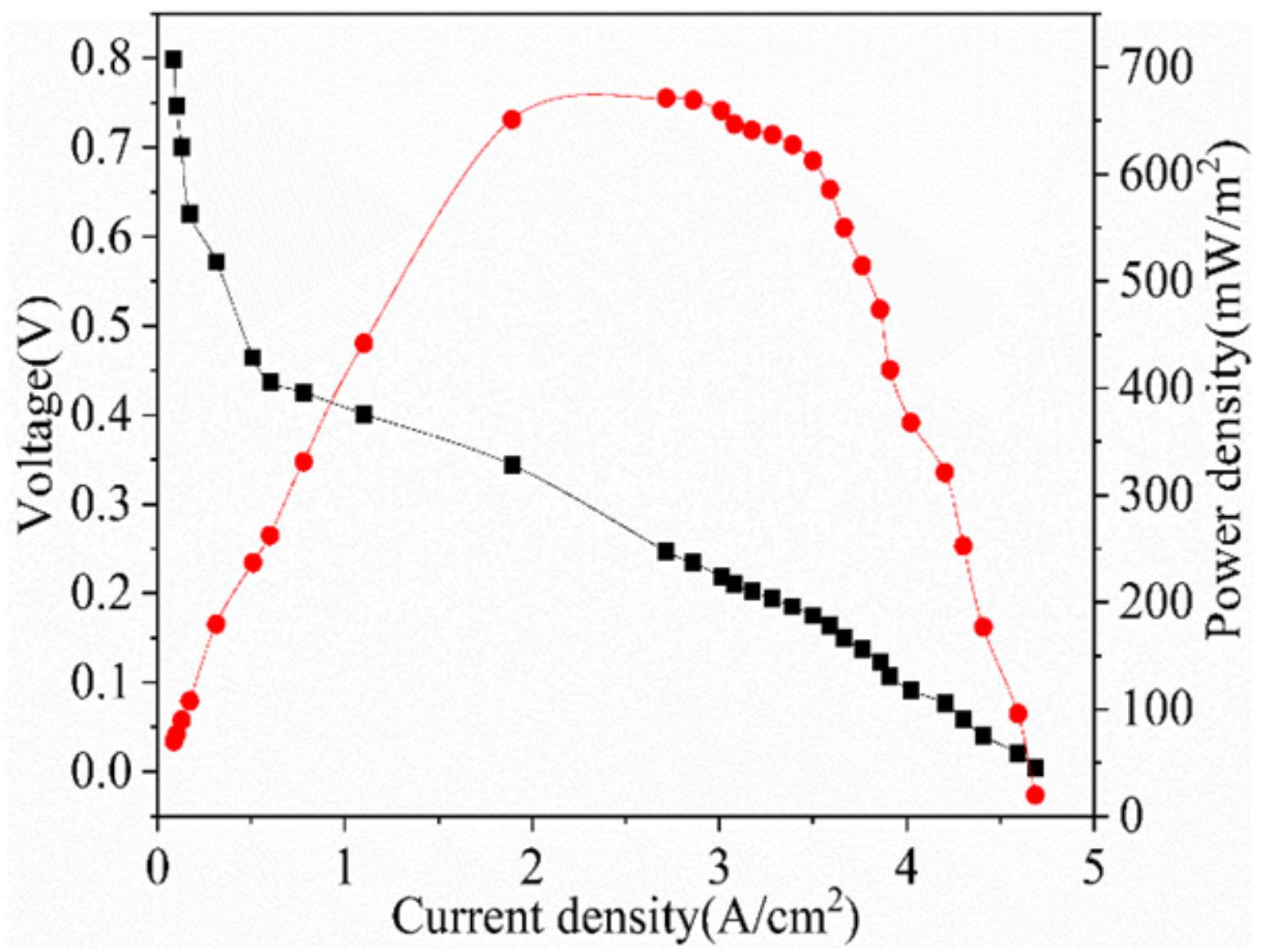

Figure 3 
Polarization and power density curve under the optimized conditions (100 r/min $+2 \mathrm{~g} / \mathrm{L})$.

Control group $100 \mathrm{r} / \mathrm{min} \quad 2 \mathrm{~g} / \mathrm{L} \quad 100 \mathrm{r} / \mathrm{min}+2 \mathrm{~g} / \mathrm{L}$
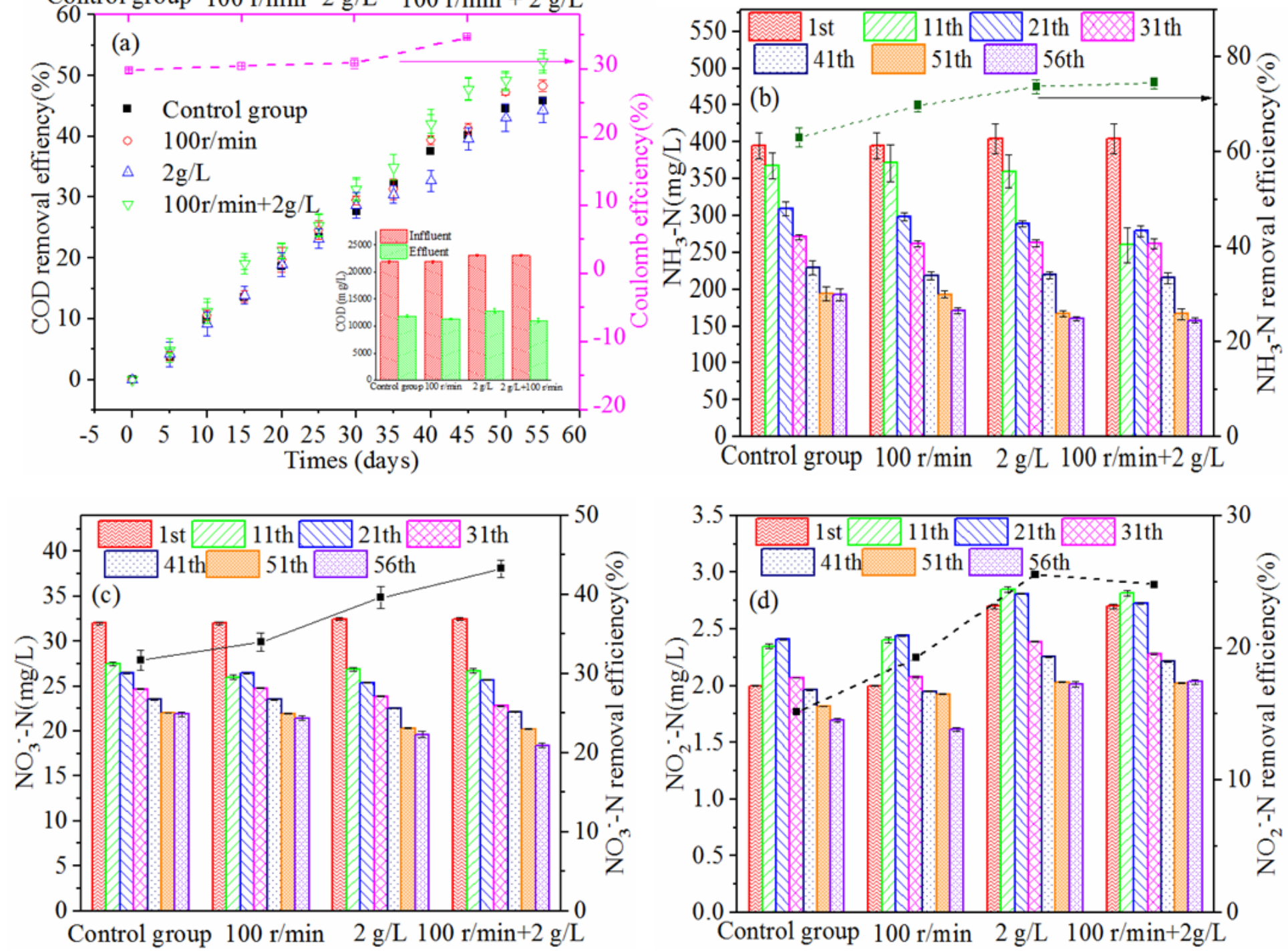

Figure 4

For the control group and the $100 \mathrm{r} / \mathrm{min}, 2 \mathrm{~g} / \mathrm{L}$ and $100 \mathrm{r} / \mathrm{min}+2 \mathrm{~g} / \mathrm{L}$ groups: (a) the COD removal rate and $\mathrm{CE}$; (b) (c) and (d) the removal concentrations of $\mathrm{NH} 3-\mathrm{N},-\mathrm{N}$ and $-\mathrm{N}$, respectively, for all anode chambers. 

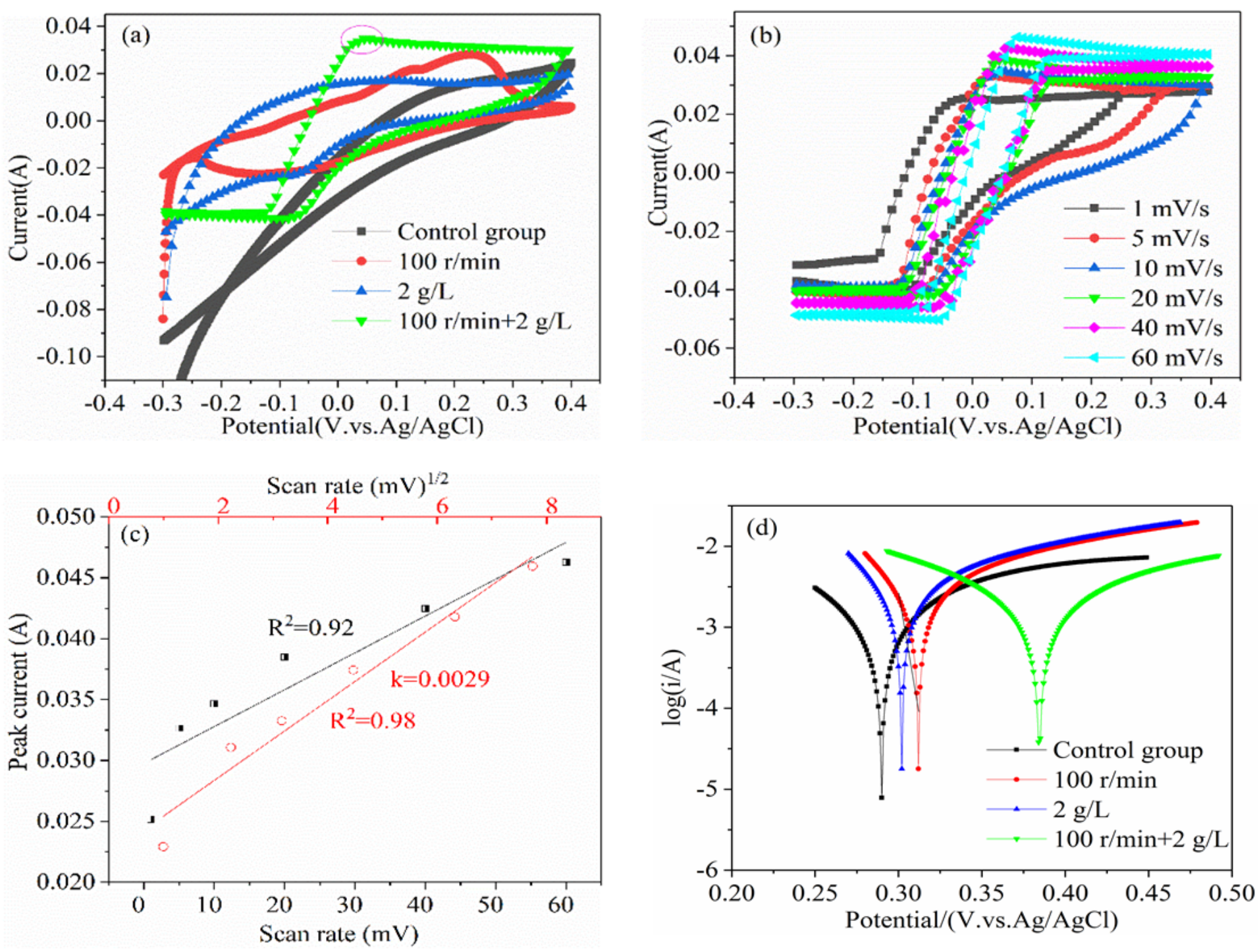

\section{Figure 5}

For the control group and the $100 \mathrm{r} / \mathrm{min}, 2 \mathrm{~g} / \mathrm{L}$ and $100 \mathrm{r} / \mathrm{min}+2 \mathrm{~g} / \mathrm{L}$ groups: (a) the COD removal rate and $\mathrm{CE}$; (b) (c) and (d) the removal concentrations of NH3-N, $-\mathrm{N}$ and $-\mathrm{N}$, respectively, for all anode chambers. 
(a)
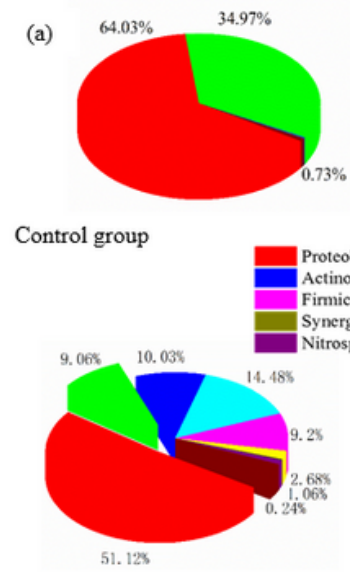

$2 \mathrm{~g} / \mathrm{L}$

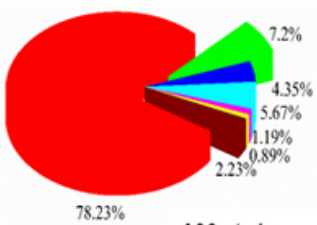

$100 \mathrm{r} / \mathrm{min}$
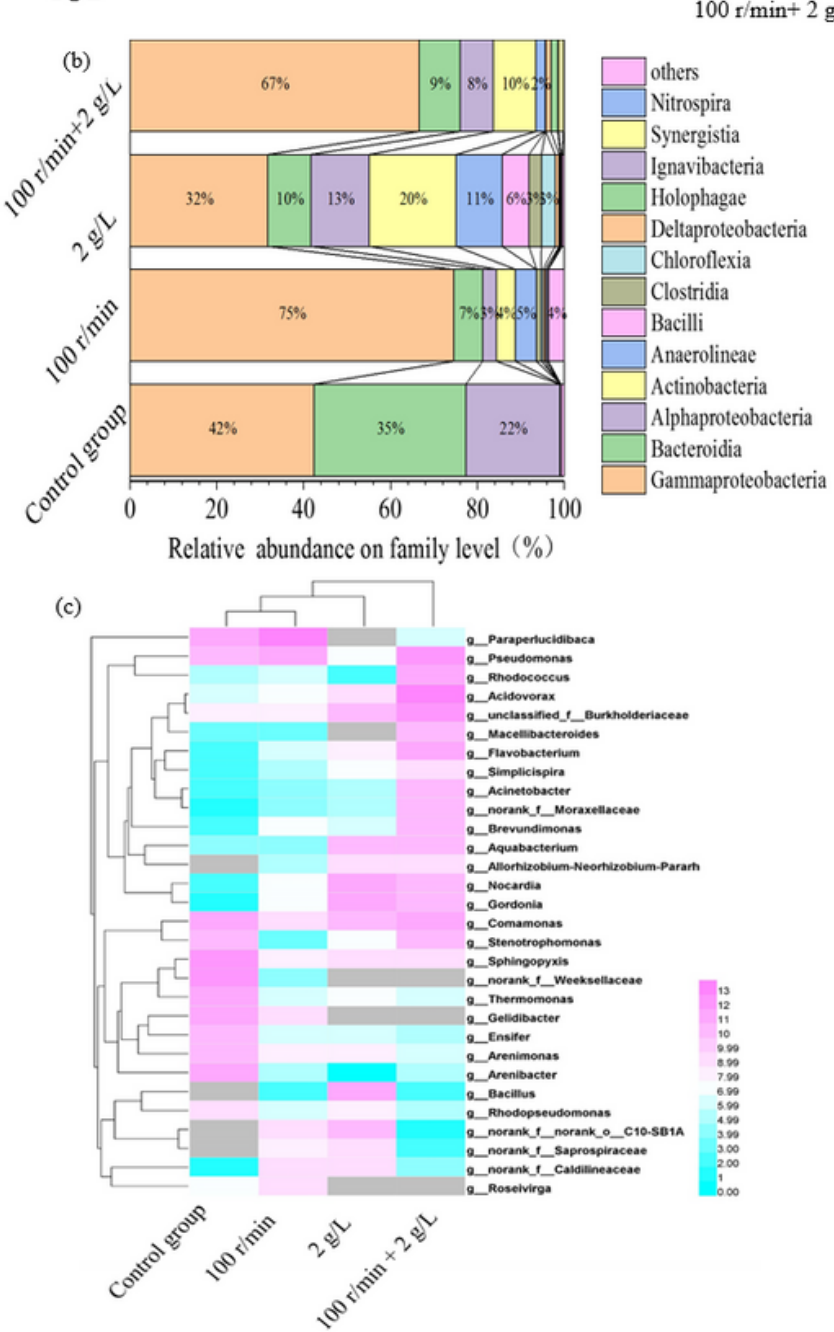

\section{Figure 6}

Microbial communities on the anode biofilms: (a) at the phylum level and (b) at the family level; (c) a sample cluster analysis and heatmap at the genus level. 


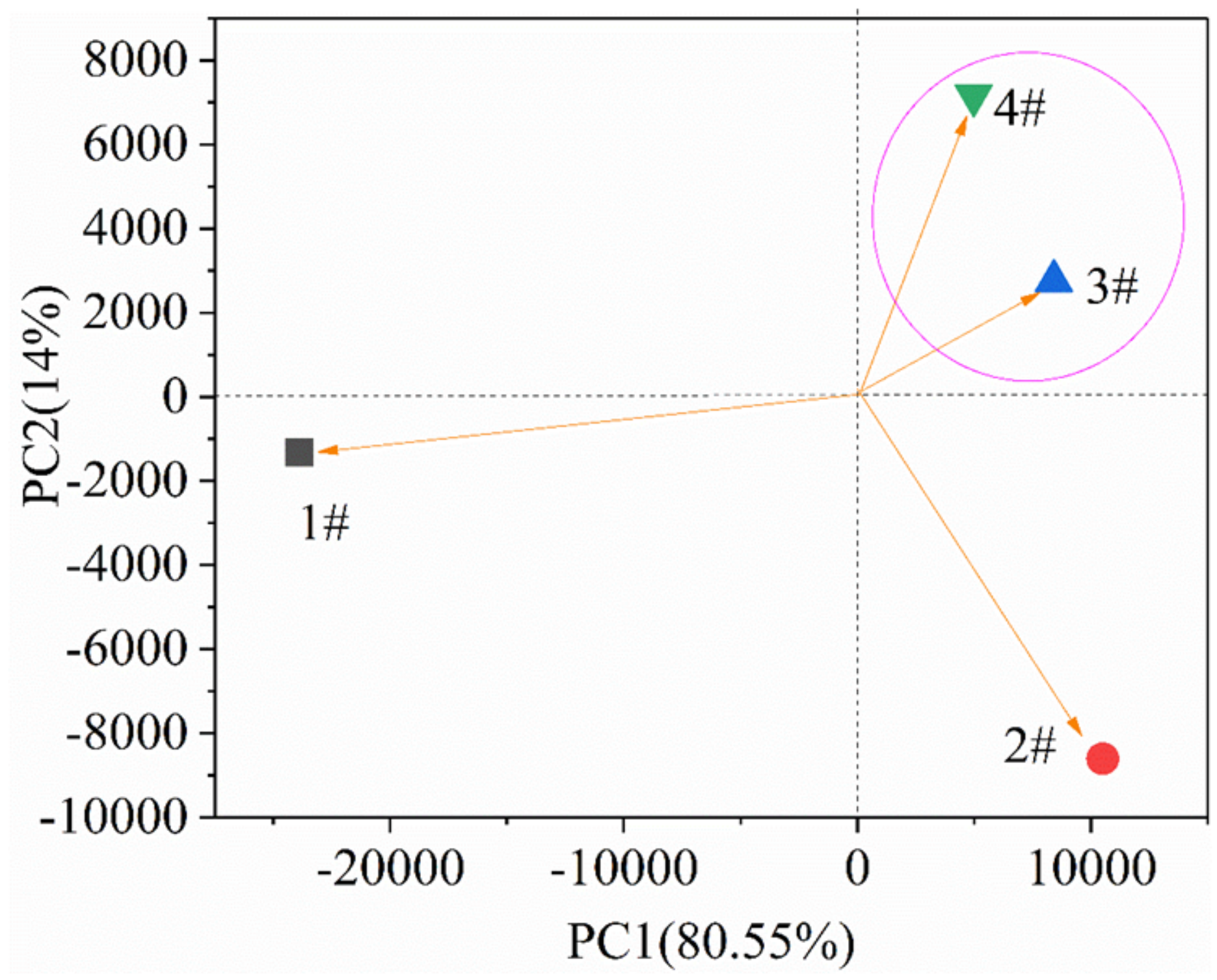

Figure 7

PCA results for the difference in OTUs of 4 samples (biofilms) based on phylogenetic lineages (1-control group, 2-group of $100 \mathrm{r} / \mathrm{min}, 3$-group of $2 \mathrm{~g} / \mathrm{L}$, and 4-group of $100 \mathrm{r} / \mathrm{min}+2 \mathrm{~g} / \mathrm{L}$ ). 

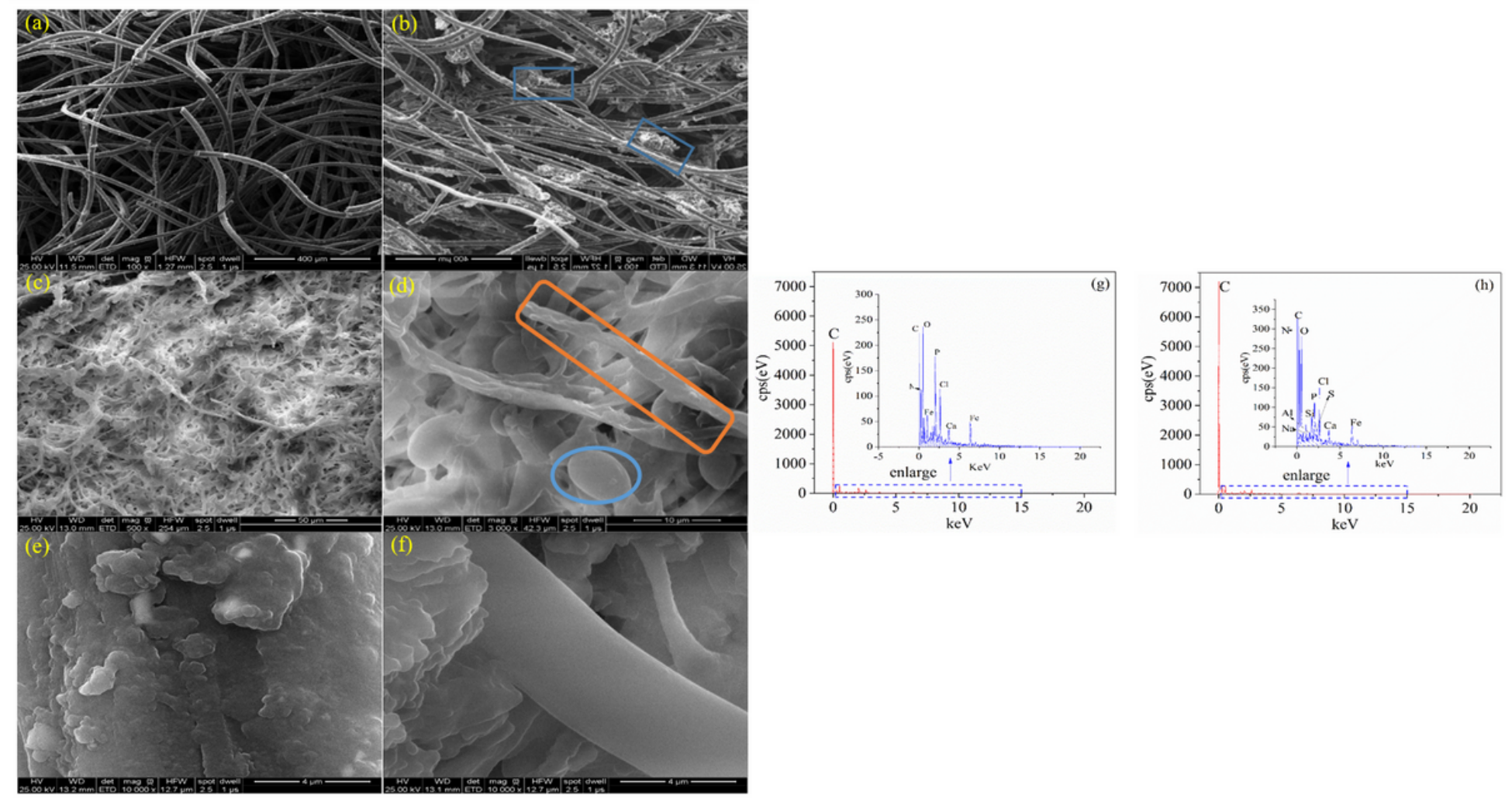

\section{Figure 8}

SEM images of anode biofilms (control group: (a), (c), and (e), and $100 \mathrm{r} / \mathrm{min}+2 \mathrm{~g} / \mathrm{L}$ : (b), (d), and (f)) and EDS spectra of the control group (g) and $100 \mathrm{r} / \mathrm{min}+2 \mathrm{~g} / \mathrm{L}(\mathrm{h})$.
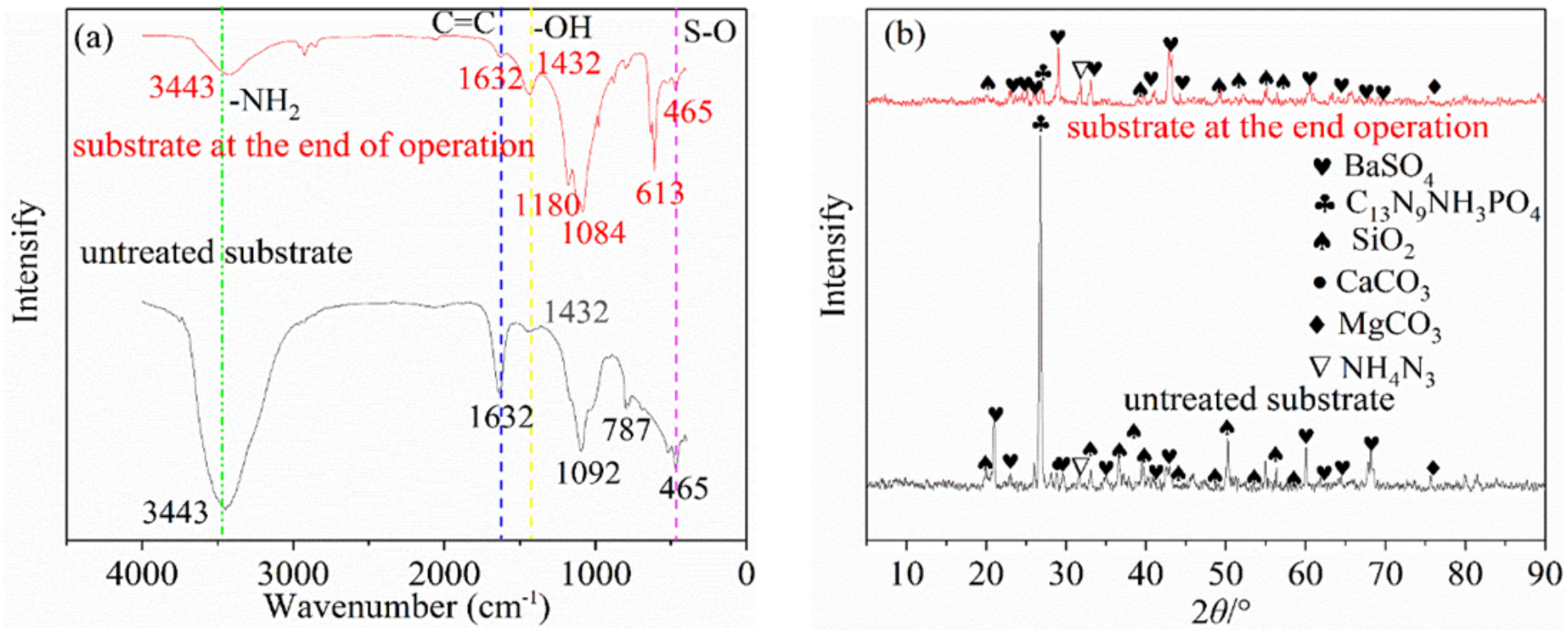

Figure 9

FT-IT (a) and XRD (b) results for the anode chamber substrate under $100 \mathrm{r} / \mathrm{min}+2 \mathrm{~g} / \mathrm{L}$ conditions. 


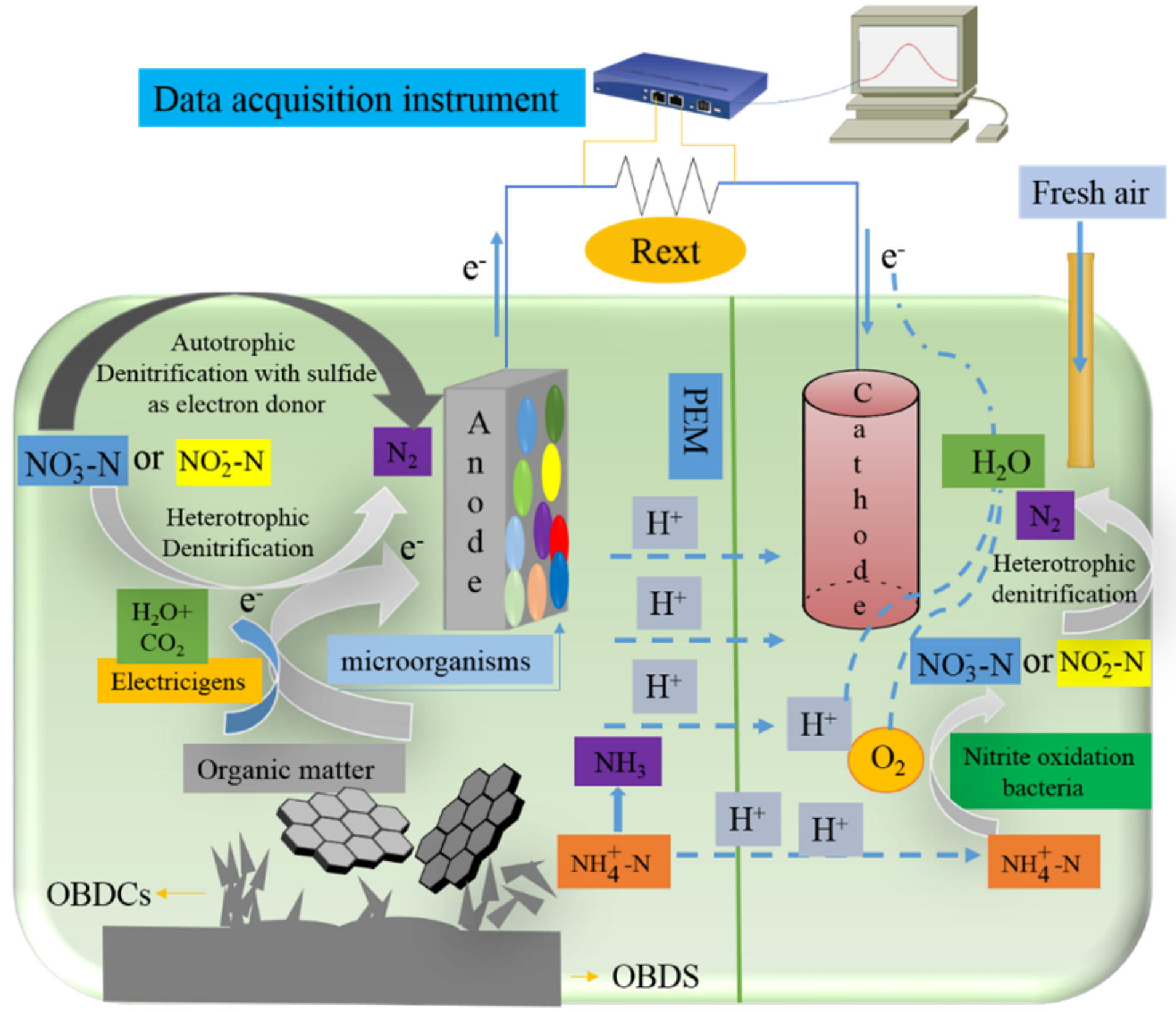

Figure 10

Schematic diagram and possible mechanism of the simultaneous removal of complex organics and nitrogen from OBDS by an MFC.

\section{Supplementary Files}

This is a list of supplementary files associated with this preprint. Click to download.

- SupplementaryMaterial.docx 